\title{
Two cases of successful pregnancies after hysteroscopic removal of endometrioid adenocarcinoma grade I, stage IA, in young women with Lynch syndrome
}

\author{
Ingrid Marton ${ }^{1}$, Hrvojka Soljacic Vranes², Vladimir Sparac ${ }^{3}$, Igor Maricic ${ }^{4}$, Krunoslav Kuna ${ }^{2}$, Miroslav Kopjar ${ }^{2}$ \\ ${ }^{1}$ Clinic of Gynecology and Obstetrics, University Hospital "Sv. Duh", Zagreb, Croatia \\ ${ }^{2}$ Clinic of Gynecology and Obstetrics, Clinical Medical Centre "SM", Zagreb, Croatia \\ ${ }^{3}$ Polyclinic of Gynecology and Obstetrics "Cito", Split, Croatia \\ ${ }^{4}$ Department of Gynecology and Obstetrics, General Hospital Zabok, Zabok, Croatia
}

\section{Abstract}

\begin{abstract}
We present two cases of endometrioid adenocarcinoma grade I, FIGO IA (staging according to the International Federation of Gynecology and Obstetrics) in young women, diagnosed within endometrial polyps. Both patients underwent repeated hysteroscopies and multiple biopsies after initial treatment to medroxyprogesterone one $400 \mathrm{mg}$ daily or the insertion of IUD-LND (intrauterine device-levonorgestrel) for three months. In both of them, all histological samples were negative. Both of them decided that they would try to conceive. The first patient conceived spontaneously and the second patient after IVF (in vitro fertilisation) treatment. They both gave birth to full-term infants. Hysterectomy was recommended to both of our patients, and was carried out. Both of the patients fulfilled both Amsterdam II and revised Bethesda criteria for hereditary non-polyposis colorectal cancer (HNPCC). (J Turk Ger Gynecol Assoc 2014; 15: 63-6)
\end{abstract}

Key words: Endometrial cancer, Lynch syndrome, hysteroscopy, reproduction

Received: 01 June, 2013

Accepted: 17 August, 2013

Available Online Date: 06 January, 2014

\section{Introduction}

Endometrial cancer is the most common invasive cancer of the female genital tract in developing countries, representing approximately $7 \%$ of all invasive malignancies in women. Primarily, it is a malignancy that occurs in postmenopausal women, with the peak of incidence between 55 and 60 years of age. According to the literature, only $3-14 \%$ of cases occur among young women $<40$ years of age (1). Lynch syndrome, also known as hereditary non-polyposis colorectal cancer (HNPCC), is associated with cancer diagnosis at an early age and the development of multiple cancer types, particularly colon and endometrial cancer (2). Women with HNPCC have a 27 to $71 \%$ risk of endometrial cancer, which equals or exceeds their risk of colorectal cancer. In addition, they have a 3 to $14 \%$ risk of ovarian cancer (3). HNPCC is an autosomal dominant inherited cancer syndrome caused by germline mutations in one of the DNA mismatch repair genes: MSH2 (also known as MutS protein homolog 2), MLH1 (MutS homolog 1), MSH6 (MutS homolog 6) and PMS2 (mismatch repair endonuclease). The risk of endometrial and ovarian cancer varies with the genotype; MSH6 mutations are associated with higher risk of endometrial cancer in comparison with MLH1 and MSH2 mutations (4). Loss of mismatch repair occurs in sporadic cancers (5). Approximately $20 \%$ of endometrial cancers are positive for microsatellite instability, but fewer than $5 \%$ are thought to be attributable to HNPCC (6). Within the manuscript, we present two cases of endometrial cancer which occurred in young women with Lynch syndrome, both of whom had achieved full term pregnancies and delivered live infants.

The aim of this case report is to show that fertility-sparing surgery (endometrial ablation in one case) is an alternative treatment for these patients, and that pregnancy after this kind of treatment is possible, even in a spontaneous cycle. 


\section{Case Presentation}

We report two cases of endometrial endometrioid cancer grade I, FIGO IA (staging according to the International Federation of Gynecology and Obstetrics). The first reported case was a woman aged 30 (nulligravida) whose family history was positive for HNPCC. Two of her uncles had been diagnosed with colon cancer at the ages of 45 and 48, and her grandmother was diagnosed with endometrial cancer. At the time of admittance, her cousin had also been admitted to the urology department due to the suspicion of a ureter malignancy.

Two years prior to admission, a uterine polyp was first diagnosed by ultrasound and followed up (Figure 1). Occasionally, she had complained of spotting. Three months before the surgery, a left ovarian cyst $4 \mathrm{~cm}$ in diameter was identified, which was suspicious of endometriosis; Doppler revealed pericystic vascularisation, RI (resistance index) 0.40. CA-125 (cancer antigen, or carbohydrate antigen) was measured and its value was $39 \mathrm{IU} / \mathrm{mL}$. Due to the family history, colonoscopy was performed, without abnormalities, and all random biopsies were negative. Laparoscopy and hysteroscopy were performed; a cyst and polyp were removed (Figure 2). Pathological review revealed endometrioid adenocarcinoma grade I and left endometriotic cyst. A month later, at repeated hysteroscopy, there was apparently no evidence of disease. Endometrial ablation was performed and all of the samples were negative. Distension media for hysteroscopy was purisol (mannitol/sorbitol mixture) and intrauterine pressure was limited to around $100 \mathrm{mmHg}$ in order to lower the risk of tumour cell spread into the peritoneal cavity. Although there might be an increased risk of peritoneal contamination by cancer cells, there is currently no evidence that these patients have a worse prognosis or propagation of the disease $(7,8)$.

Hysterectomy as a definitive treatment was discussed with the patient, but she chose a conservative approach with high dose progesterone treatment for 3 months (400 mg medroxyprogesterone per day) and to attempt to conceive. A month after completing her hormonal treatment, a third diagnostic hysteroscopic biopsy was performed and histopathology was negative. The patient was under the constant surveillance of her gynaecological endocrinologist due to the relatively thin endometrium; and therefore received oestrogen supplementation during her menstrual cycle. Three months after the procedure, she conceived spontaneously and vaginally delivered a full term infant. Three months after the delivery, an operative procedure was performed. 3DPD (3D power Doppler) and MRI (magnetic resonance imaging) of the abdomen and pelvis were performed prior to surgery. There was no sign of myometrial invasion. During the operation, peritoneal washing for cytological sampling was performed (negative), and a frozen section was taken. Due to the result of the frozen section (locus of the hyperplasia complex atypica), there was no indication for pelvic lymphadenectomy. Hysterectomy was performed, but the patient refused the suggested adnexectomy, although she was presented with the risk of ovarian malignancy and the necessity of further follow-ups. Postoperative pathology revealed hyperplasia complex atypical and EIN (endometrial intraepithelial neoplasia).
The second reported case was a 39 year old woman (nullipara, secundigravida) who had already been operated upon for primary colon carcinoma 9 years prior to admittance. Her family history was positive for HNPCC according to the Amsterdam II criteria. Both her father and grandfather died

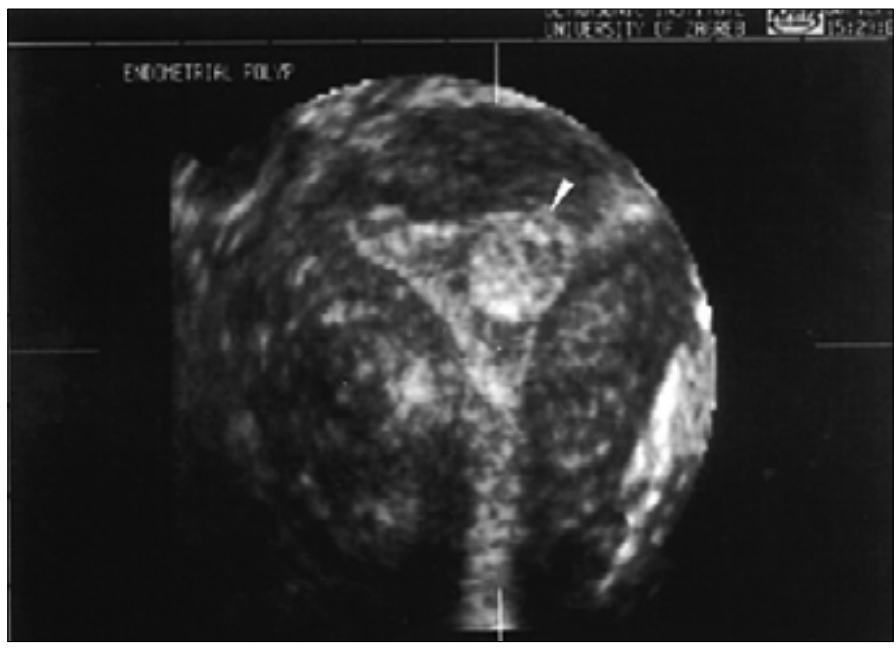

Figure 1. An endometrial polyp diagnosed by 3D ultrasound

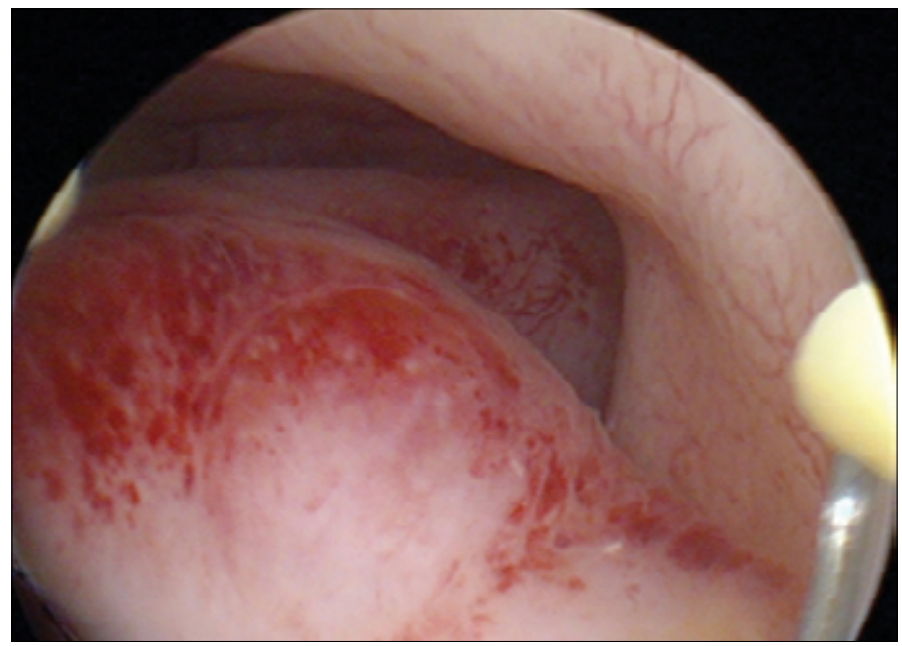

Figure 2. An endometrial polyp shown by hysteroscopy

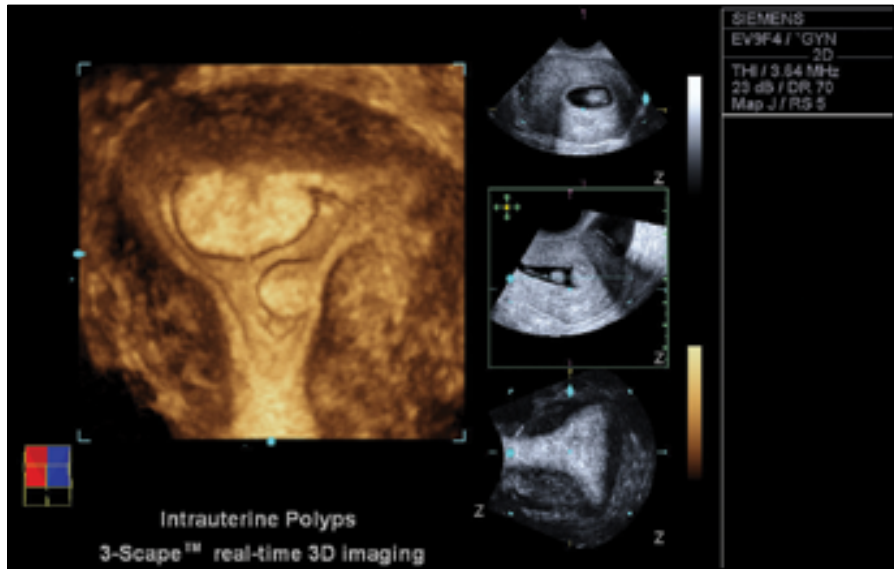

Figure 3. Coronal and transversal plains of uterus. Endometrial polyp within the uterine cavity 


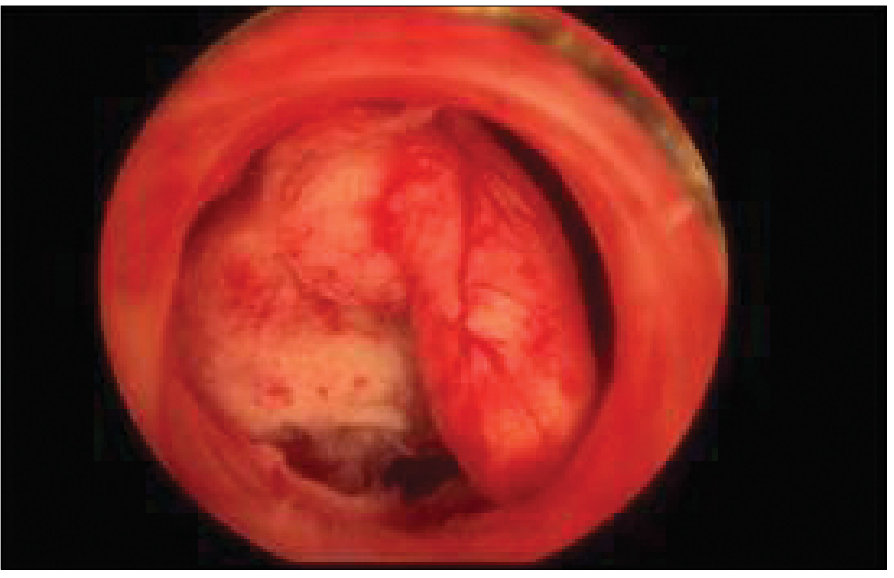

Figure 4. Clear visualisation of uterine polyp, shown by minimally invasive operative procedure

due to colorectal carcinoma, and a second degree relative had been diagnosed with small intestine cancer. She was admitted to our clinic because of the suspicion of an endometrial polyp, taking into the consideration her anamnesis (Figure 3). At the time of admittance, she had no complaints. Hysteroscopy was performed, and several polyps were removed (Figure 4). Pathological examination revealed endometrioid adenocarcinoma grade I on one of the polyps and hyperplasia glandularis complex atypica on the other sample. After the counselling, hysteroscopy was repeated in a month. One out of ten samples was positive for hyperplasia atypica. The patient refused suggested hysterectomy. We agreed to continue her treatment with IUD-LNG for a period of three months. Hysteroscopic biopsies of the endometrium were performed again, and all samples were negative. The patient tried to conceive spontaneously, but suffered a miscarriage. After unsuccessful trials of spontaneous conception, she was immediately referred for an IVF procedure; approximately 10 months after the initial procedure, she gave birth to a term infant. Three months after the delivery she underwent an operative procedure: including peritoneal washing for cytological sampling and hysterectomy. Frozen sections revealed endometrioid cancer grade I without myometrial invasion, and therefore without any further need for pelvic lymphadenectomy, but adnexectomy was performed. Peritoneal washing was negative. Postoperative pathology confirmed intraoperative diagnosis.

Both patients were operated on three months after the delivery because both of them insisted on completing puerperium and preparing physically and emotionally for the operation; also, according to the literature, there were no strict disadvantages to this delay.

Both of our patients fulfilled both Amsterdam criteria II and revised Bethesda criteria for HNPCC. In the first case, as the size of the polypoid tumour extracted from her uterine cavity was too small for microsatellite instability (MSI) testing, and as we could not obtain a colon cancer tumour sample from her affected relative, we proceeded with DNA blood analysis at the commercial facility of Myriad Genetic Laboratories, Seattle, WA. Gene sequencing and MSI testing was performed.
Complete sequencing of the MLH1 and MSH2 genes was performed in the first case, but the results were negative. MSH6 analysis identified a mutation. In the second case, the polypoid tumour showed a high-frequency (MSI-H) phenotype, as in the colon cancer samples.

According to our results, we have not observed worsening of the pathohistological findings, probably due to the surgical and hormonal therapy, and normal placental endocrine activity, which is considered to have a therapeutic effect due to natural, extremely high-dose progestin.

\section{Discussion}

The diagnosis of endometrial cancer in young women may be delayed due to the presenting symptoms of vaginal bleeding, which is often considered dysfunctional. Whenever there is a positive family history, HNPCC should be suspected. Hysteroscopy is considered to be a gold standard for the evaluation of endometrial pathologies. Transvaginal ultrasound is still considered a first-line diagnostic procedure in detecting endometrial cancer in postmenopausal women without abnormal uterine bleeding, because it is not invasive and it has high sensitivity for detecting endometrial cancer; however, outpatient hysteroscopy with biopsy is absolutely mandatory in all postmenopausal women with abnormal uterine bleeding (9). According to the data from the literature, it is possible that hysteroscopy in patients with endometrial cancer poses a risk for cancer cell dissemination within the peritoneal cavity (10), but other data suggest that hysteroscopy has no adverse effect on the incidence of positive peritoneal washings or on prognosis in stage I endometrial cancer patients (7). Myometrial invasion is the most important prognostic factor for endometrial cancer and could be suspected either by transvaginal sonography and/ or magnetic resonance imaging. They share similar specificity and sensitivity of approximately $90 \%$. Women with low grade (grade 1 or 2) endometrioid cancers confined to the endometrium (stage IA) are classified as having low-risk disease. The overall probability of recurrence in this group is very low following surgical treatment alone (11). Standard therapy in endometrioid cancer FIGO IA cases consists of hysterectomy, which could be performed either by conventional laparoscopy, robotic surgery, vaginally or by open surgery. Systematic lymphadenectomy for this stage is not indicated. Both cases were endometrioid adenocarcinoma grade I, FIGO IA. Both of the patients have fulfilled the Amsterdam II and revised Bethesda criteria for HNPCC. Criteria known as Amsterdam and Bethesda are sets of diagnostic criteria used to identify families and individuals who are likely to have Lynch syndrome or HNPCC (12). Because both of the patients had not completed their reproduction at the time of diagnosis, we had to consider conservative treatments prior to hysterectomy. The first case reports regarding conservative treatment of endometrial cancer were published in the early 1960s. Since then, the safety and efficacy of hormonal therapy as a primary treatment of endometrial cancer in reproductive age have been reported in several articles $(13,14)$. Lately, papers have been published about hysteroscopic resection of the endometrium in order to preserve fertility (15), and 
hysteroscopic endomyometrial resection as an alternative treatment to hysterectomy for an early stage endometrial cancer in both pre- and postmenopausal women (16).

In conclusion, conservative treatment in young women who have not completed their reproduction and desire the preservation of fertility may be considered an option. All treatment options should be discussed in detail with a patient. Strict selection criteria are of the highest importance, such as age, FIGO classification, histological type and grade of the tumour, reproduction. Careful follow-up is mandatory.

\section{Ethics Committee Approval: N/A}

Informed Consent: Informed consent was received from the participants of this study.

Peer-review: Externally peer-reviewed.

Author contributions: All of the authors actively and equally participated in the creation of the manuscript and fully meet the criteria of authorship.

Conflict of Interest: No conflict of interest was declared by the authors.

Financial Disclosure: The authors declared that this study received no financial support.

\section{References}

1. Siegel R, Naishadham D, Jemal A. Cancer Statistics, 2013. CA Cancer J Clin 2013; 63: 11-30. [CrossRef]

2. Fishel R, Lescoe MK, Rao MR, Copeland NG, Jenkins NA, Garber J, et al. The human mutator gene homolog MSH2 and its association with hereditary nonpolyposis colon cancer. Cell 1993; 75: 1027-38. [CrossRef]

3. Barrow E, Robinson L, Alduaij W, Shenton A, Clancy T, Lalloo F, et al. Cumulative lifetime incidence of extracolonic cancers in Lynch syndrome: a report of 121 families with proven mutations. Clin Genet 2009; 75: 141. [CrossRef]

4. Watson P, Vasen HF, Mecklin JP, Bernstein I, Aarnio M, Järvinen $\mathrm{HJ}$, et al. The risk of extra-colonic, extra-endometrial cancer int he Lynch syndrome. Int J Cancer 2008; 123: 444-9. [CrossRef]

5. Stefansson I, Akslen LA, MacDonald N, Ryan A, Das S, Jacobs IJ, et al. Loss of hMSH2 and hMSH6 expression is frequent in sporadic endometrial carcinomas with microsatelite instability: a population-based study. Clin Cancer Res 2002; 8: 138-43.

6. Dunlop MG, Farrington SM, Nicholl I, Aaltonen L, Petersen G, Porteous M, et al. Population carrier frequency of hMSH2 and hMLH1 mutations. Br J Cancer 2000; 83: 1643. [CrossRef]

7. Biewenga $\mathrm{P}$, de Blok S, Birnie E. Does diagnostic hysteroscopy in patients with stage I endometrial carcinoma cause positive peritoneal washings? Gynecol Oncol 2004; 93: 194-8. [CrossRef]

8. Revel A, Tsafrir A, Anteby SO, Shushan A. Does hysteroscopy produce intraperitoneal spread of endometrial cancer cell? Obstet Gynecol 2004; 59: 280-4.

9. Litta P, Merlin F, Saccardi C, Pozzan C, Sacco G, Fracas M, Capobianco G, Dessole S. Role of hysterocopy with endometrial biopsy to rule out endometrial cancer in postmenpausal women with abnormal uterine bleeding. Maturitas 205; 50:117-23.

10. Polyzos NP, Mauri D, Tsioras S, Messini CI, Valachis A, Messinis IE. Intraperitoneal dissemination of endometrial cancer cells after hysteroscopy: a systematic review and meta-analysis. Int J Gynecol Cancer 2010; 20: 261-7. [CrossRef]

11. Grigsby PW, Perez CA, Kuten A, et al. Clinical stage I endometrial cancer: prognostic factors for local control and distant metastasis and implications oft he new FIGO surgical staging system. Int J Radiat Oncol Biol Phys 1992; 22: 905. [CrossRef]

12. Piñol V, Castells A, Andreu M, Castellví-Bel S, Alenda C, Llor X, et al. Accuracy of revised Bethesda guidelines, microsatelite instability, and imunohistochemistry fot the identification of patients with hereditary nonpolyposis colorectal cancer. JAMA 2005; 293: 1986-94. [CrossRef]

13. Gotlieb WH, Beiner MR, Shalmon B, Korach Y, Segal Y, Zmira N, et al. Outcome of fertility-sparing treatment with progestins in young patients with endometrial cancer. Obstet Gynecol 2003; 102: 718-25. [CrossRef]

14. Signorelli M, Caspani G, Bonazzi C, Chiappa V, Perego P, Mangioni C. Fertility-sparing treatment in young women with endometrial cancer or atypical complex hyperplasia: a prospective single-institution experince of 21 cases. BJOG 2008; 116: 114-8. [CrossRef]

15. Martinez A, Poilblanc M, Ferron G, De Cuypere M, Jouve E, Querleu D. Fertility-preserving surgical procedures, techiques. Best Pract Res Clin Obstet Gynecol 2012; 26: 407-24. [CrossRef]

16. Vilos GA, Ettler HC, Edrs F, Hollett-Caines J, Abu-Rafea B. Endometroid adenocarcinoma treated by hysteroscopic endometrial resection. J Minim Invasive Gynaecol 2007; 14: 119-22. [CrossRef] 